\title{
The Patient Health Questionnaire-9 as a Screening Tool for Depression in Individuals with Type 2 Diabetes Mellitus: The Maastricht Study
}

Citation for published version (APA):

Janssen, E. P. C. J., Köhler, S., Stehouwer, C. D. A., Schaper, N. C., Dagnelie, P. C., Sep, S. J. S., Henry, R. M. A., van der Kallen, C. J. H., Verhey, F. R., \& Schram, M. T. (2016). The Patient Health Questionnaire-9 as a Screening Tool for Depression in Individuals with Type 2 Diabetes Mellitus: The Maastricht Study. Journal of the American Geriatrics Society, 64(11), E201-E206. https://doi.org/10.1111/jgs.14388

Document status and date:

Published: 01/11/2016

DOI:

10.1111/jgs. 14388

Document Version:

Publisher's PDF, also known as Version of record

Document license:

Taverne

Please check the document version of this publication:

- A submitted manuscript is the version of the article upon submission and before peer-review. There can be important differences between the submitted version and the official published version of record.

People interested in the research are advised to contact the author for the final version of the publication, or visit the DOI to the publisher's website.

- The final author version and the galley proof are versions of the publication after peer review.

- The final published version features the final layout of the paper including the volume, issue and page numbers.

Link to publication

\footnotetext{
General rights rights.

- You may freely distribute the URL identifying the publication in the public portal. please follow below link for the End User Agreement:

www.umlib.nl/taverne-license

Take down policy

If you believe that this document breaches copyright please contact us at:

repository@maastrichtuniversity.nl

providing details and we will investigate your claim.
}

Copyright and moral rights for the publications made accessible in the public portal are retained by the authors and/or other copyright owners and it is a condition of accessing publications that users recognise and abide by the legal requirements associated with these

- Users may download and print one copy of any publication from the public portal for the purpose of private study or research.

- You may not further distribute the material or use it for any profit-making activity or commercial gain

If the publication is distributed under the terms of Article $25 \mathrm{fa}$ of the Dutch Copyright Act, indicated by the "Taverne" license above, 


\title{
The Patient Health Questionnaire-9 as a Screening Tool for Depression in Individuals with Type 2 Diabetes Mellitus: The Maastricht Study
}

\author{
Eveline P. C. J. Janssen, MD, ${ }^{* \dagger}$ Sebastian Köhler, PhD, ${ }^{*}$ Coen D. A. Stehouwer, MD, PhD, ${ }^{\text {s๘ }}$ \\ Nicolaas C. Schaper, MD, PhD,,$^{\$ \uparrow *}$ Pieter C. Dagnelie, MD, PhD, "*广 Simone J. S. Sep, PhD, \\ Ronald M. A. Henry, MD, PhD, Carla J. H. van der Kallen, PhD, ${ }^{\text {s๘ }}$ Frans R. Verhey, MD, PhD, \\ *t and Miranda T. Schram, PhD ${ }^{s+1}$
}

OBJECTIVES: To assess the psychometric properties and identify the best cutoff value of the Patient Health Questionnaire-9 (PHQ-9) for depression screening in individuals with type 2 diabetes mellitus (T2DM).

DESIGN: Observational population-based cohort study.

SETTING: The Maastricht Study.

PARTICIPANTS: Individuals with and without T2DM (mean age $58.6 \pm 8.1,44.6 \%$ male) according to an oral glucose tolerance test $(\mathrm{N}=2,997)$.

MEASUREMENTS: Depressive disorder and depressive symptoms were measured using the Mini-International Neuropsychiatric Interview (MINI) as the reference and the PHQ9. Cronbach alpha, Cohen's kappa and receiver operating characteristic (ROC) analyses were used. Differences in factorial structure between participants with and without T2DM were tested using multigroup confirmatory factor analysis.

RESULTS: Based on the traditional PHQ-9 cutoff value, $133(4.4 \%)$ participants had depressive symptoms (PHQ-9 score $\geq 10$ ). Internal consistency of the PHQ-9 was good (Cronbach $\alpha=0.87$ with T2DM, 0.82 without T2DM), the kappa of agreement between the PHQ-9 and the MINI was moderate ( 0.40 with T2DM, 0.43 without T2DM). Area under the ROC curve for the PHQ-9 was 0.87 in participants with T2DM and 0.88 in those without. A PHQ-9 cutoff score of 5 provided the best sensitivity $(92.3 \%)$, with acceptable specificity $(70.4 \%)$, for T2DM,

From the *Department of Psychiatry and Neuropsychology, Maastricht University Medical Center, Maastricht; ${ }^{\dagger}$ Mondriaan Department of Old Age Psychiatry, Heerlen; ${ }^{\star} \mathrm{MHeNs}$ School for Mental Health and

Neuroscience, Maastricht University; ${ }^{\S}$ Department of Internal Medicine, Maastricht University Medical Center; ${ }^{\text {9C }}$ ardiovasculair Research Institute Maastricht; *CAPHRI School for Public Health and Primary Care; and

${ }^{\dagger}$ Department of Epidemiology, Maastricht University, Maastricht, the Netherlands.

Address correspondence to Eveline Janssen, Mondriaan Department of Old Age Psychiatry, John F Kennedylaan 301, Heerlen 6419 XZ, the

Netherlands. E-mail: ejanssen.uop@gmail.com

DOI: $10.1111 /$ jgs. 14388 similar to sensitivity and specificity in individuals without T2DM. Factor analysis suggested a similar two-factor structure in both groups (affective and somatic symptoms). CONCLUSION: Patient Health Questionnaire-9 performs well as a screening tool for depressive symptoms in individuals with and without T2DM based on the cutoff value of 5, indicating that the PHQ-9 can be used in two-stage screening in primary care to select individuals with T2DM for further psychological evaluation. J Am Geriatr Soc 64: e201-e206, 2016.

Key words: diabetes mellitus type 2; depressive disorder; Patient Health Questionnaire-9; Mini-International Neuropsychiatric Interview; screening

$T$ ype 2 diabetes mellitus (T2DM) is a chronic metabolic disorder, and psychological comorbidity such as depression is prevalent. ${ }^{1}$ Meta-analyses have demonstrated that a depressive disorder is nearly twice as prevalent in individuals with T2DM than in the general population, with a prevalence of $8 \%$ to $43.5 \% .^{2-5}$ Depression in individuals with T2DM is associated with poorer quality of life, ${ }^{6}$ poorer self-care, greater healthcare use, poorer glycemic control, and subsequently higher healthcare costs. ${ }^{6-10}$ The poorer glycemic control in individuals with T2DM with depressive symptoms may, at least in part, explain the excess risk of DM-related complications and mortality in these individuals. ${ }^{8-12}$ Therefore, early detection and treatment of depressive symptoms in individuals with T2DM may decrease complications and mortality and help to prevent a more-severe depressive disorder. ${ }^{13}$ The negative effects of depression in individuals with T2DM are not limited to those with severe depression but have also been observed in individuals with relatively mild or 
subclinical depression. ${ }^{9,14}$ It is recommended that individuals with T2DM be systematically screened for depression, ${ }^{15}$ but this has not been implemented in primary and referral diabetes mellitus healthcare settings in most countries, indicating that validated, standardized methods for depression screening are needed in guidelines for T2DM treatment.

Several questionnaires have been developed to assess depressive symptoms, of which the 9-item Patient Health Questionnaire (PHQ-9) is frequently used. ${ }^{16,17}$ The predictive value of the PHQ-9 has been studied in small samples of individuals with T2DM for major and in some studies also for minor depressive disorder. ${ }^{18-21}$ The questionnaire performed well as a screening instrument in comparison with the reference standards (clinical interview or the Mini-International Neuropsychiatric Interview $(\mathrm{MINI})^{22}$ ), but each study used a different cutoff value for the PHQ9. ${ }^{18-20}$ Factor analytical studies in the general population or in individuals with depression suggest that the PHQ-9 consists of two correlated factors measuring affective and somatic symptoms of depression, ${ }^{23,24}$ yet it is unknown whether the factor structure is similar for individuals with and without T2DM, in particular because somatic symptoms of depression might occur more often in individuals with T2DM.

Before the PHQ-9 can be implemented in daily clinical diabetes care, further psychometric evaluation of the questionnaire is required in a large group of individuals with T2DM. Furthermore, the best cutoff value of the PHQ-9 has to be identified, taking into account a prevalence of depression of less than $10 \%$ in the target population. ${ }^{25}$

The aims of the present study were to identify the best cutoff value for the PHQ-9 questionnaire in individuals with and without T2DM using the MINI diagnostic interview as the reference standard and to test the psychometric properties of the PHQ-9 in individuals with and without T2DM.

\section{METHODS}

\section{Study Population}

Data from the Maastricht Study, an observational population-based cohort study, were used. The rationale and methodology have been described previously. ${ }^{26}$ In brief, the study focuses on the etiology, pathophysiology, complications, and comorbidities of T2DM and is characterized by an extensive phenotyping approach. All individuals aged 40 and 75 living in the southern part of the Netherlands were eligible for participation. Participants were recruited through mass media campaigns and from the municipal registries and the regional Diabetes Patient Registry using mailings. Recruitment was stratified according to known T2DM status for reasons of efficiency. The present report includes cross-sectional data from the first 3,451 participants, who completed the baseline survey between November 2010 and September 2013. Examinations of each participant were performed within a time window of 3 months. The institutional medical ethical committee (NL31329.068.10) and the Minister of Health, Welfare and Sports of the Netherlands approved the study on the basis of the Health Council's opinion (Permit
131088-105234-PG). All participants provided written informed consent.

\section{Assessment of T2DM Status}

To determine glucose metabolism defined according to the World Health Organization 2006 criteria, ${ }^{27}$ all participants except those using insulin underwent an oral glucose tolerance test after an overnight fast. ${ }^{26}$ Participants using glucose-lowering medication were classified as having T2DM. Individuals with type 1 diabetes mellitus were excluded from the analyses.

\section{Assessment of Depression}

Major and minor depressive disorders according to Diagnostic and Statistical Manual of Mental Disorders, Fourth Edition (DSM-IV) criteria were assessed using the MINI, a short diagnostic structured interview. ${ }^{22,26}$ Major depressive disorder was diagnosed if participants had at least one core symptom (depressed mood or loss of interest) and at least four other symptoms of depression (significant weight change or change in appetite, insomnia or hypersomnia, psychomotor agitation or retardation, fatigue or loss of energy, guilt or worthlessness, diminished ability to think or concentrate or indecisiveness, and suicidal thoughts or plans). Persons with one core symptom and one to three other symptoms were classified as having a minor depressive disorder. The term "depression" in this study refers to participants with major or minor depressive disorder.

Depressive symptoms were assessed using a validated Dutch version of the PHQ-9, a self-administered questionnaire based on the DSM-IV criteria for a major depressive disorder. ${ }^{17}$ The PHQ-9 measured cognitive (thoughts about oneself and problems of the mind) and somatic symptoms of depression (various bodily sensations that a depressed individual perceives as unpleasant or worrisome). The questionnaire comprises nine items each rated on a 4-point scale ranging from 0 (not at all) to 3 (nearly every day). Response options are used to calculate a continuous total score ranging from 0 to 27 ; as a continuous variable, scores of 9 or less indicate no depression, 10 to 14 moderate depression, 15 to 19 moderately severe depression, and 20 to 27 severe depression. A predefined cutoff score of 10 can be used as a dichotomous scoring system for defining clinically relevant depressive symptoms. ${ }^{17}$

\section{Statistical Analysis}

Statistical analyses were performed using SPSS version 20.0 (IBM Corp, Armonk, NY) and Mplus 7 (Muthén \& Muthén, Los Angeles, CA). Dichotomous data were analyzed using the chi-square test and continuous data using an independent-samples $t$-test. The interitem consistency of the PHQ-9 was measured according to Cronbach alpha. Agreement between the MINI and PHQ-9 was measured according to Cohen's kappa. Receiver operating characteristics (ROC) analyses were used to assess the sensitivity, specificity, and positive and negative predictive value and to test for overall accuracy and unweighted $\mathrm{k}$ for cutoff points on the PHQ-9. In this study on screening 
characteristics, higher sensitivity of the PHQ-9 is preferred over good specificity.

To assess whether PHQ-9 specific items (e.g., somatic or affective symptoms) are related to different latent dimensions of depression, confirmatory factor analysis was conducted, following a strategy described previously. ${ }^{23}$ The PHQ-9 consists of Likert-type items that were treated as ordinal variables by specifying a mean and variance-corrected weighted least squares estimator. The model with the best fit was chosen based on the root mean square error of approximation (RMSEA, <.05 indicates close fit), Comparative Fit Index, and Tucker-Lewis Index (values $>0.95$ indicate close fit for both). Chi-square is also reported $(P>.05$ desirable), although it is sensitive to sample size and is often significant in even only moderately large samples. Finally, measurement invariance was tested to evaluate whether the factor model is similar for participants with and without T2DM (multigroup confirmatory factor analysis). In the case of strong factorial invariance, groups have the same factor pattern (same number of factors and same items correlating with the same factors), intercepts (or item thresholds in the case of ordinal items), and factor loadings. ${ }^{28}$

\section{RESULTS}

\section{Demographical and Clinical Characteristics}

Of the 3,451 participants, 454 were excluded from the analyses because they had Type 1 or other type of diabetes $(\mathrm{n}=41)$ or missing MINI $(\mathrm{n}=141)$ or PHQ-9 $(\mathrm{n}=294)$ values (Figure S1). Of the remaining 2,997 participants, $793(26.5 \%)$ had T2DM. Depressive disorder, according to the MINI, was present in $61(7.7 \%)$ participants with T2DM and in $88(4.0 \%)$ of those without.

Demographical and clinical characteristics according to T2DM and depression status are presented in Table 1 . Significant differences were found in all demographic characteristics, lifestyle factors, clinical characteristics, and use of medication, except for sleep medication, between participants with and without T2DM.

In the T2DM group, individuals with current depression had higher glycosylated hemoglobin levels and were significantly more likely to report lifetime depression; to be current smokers; and to use antidepressants, anxiolytics, and antipsychotics than those who did not have depression.

Individuals with T2DM with depression were significantly more often male; were older; had a higher body mass index; and more often reported prior cardiovascular disorders, hypertension, and use of glucose-lowering medication, statins, and antihypertensives than those without T2DM.

\section{Agreement Between PHQ-9 and MINI Diagnostic Interview}

Based on the traditional PHQ-9 cutoff value of 10, 133 $(4.4 \%)$ participants, 57 with and 76 without T2DM, were found to have depressive symptoms. The internal consistency of the PHQ-9 was good, and Cronbach alpha was 0.87 for individuals with T2DM and 0.82 for those without. The kappa measure of agreement between PHQ-9 with a cutoff score of 10 and the MINI was moderate (0.40 with T2DM, 0.43 without).

In the group with T2DM, overlap between a MINI diagnosis of depression and presence of a PHQ-9 score of 10 or greater was small (Table 2). Sensitivity was $42.6 \%$, and specificity was $95.7 \%$, with a positive predictive value of $45.6 \%$ and a negative predictive value of $95.8 \%$ (Table 3). Similar poor results were found in the group without T2DM and the total population (Table 3).

\section{ROC Analyses}

Receiver operating characteristic analyses were performed to define a potential better cutoff value for the PHQ-9. These analyses showed an area under the ROC curve (AUC) of 0.87 in individuals with T2DM and 0.88 in those without (both good). When the groups were combined, an AUC of 0.88 was found (Figure S2). Table 3 illustrates that a PHQ-9 cutoff score of 5 provided the best sensitivity $(92.3 \%)$, with moderate but still acceptable specificity $(70.4 \%)$ for individuals with T2DM. Sensitivity for individuals without T2DM was $92.9 \%$, and specificity was $73.9 \%$.

\section{Factor Structure}

Confirmatory factor analysis was performed following a previously reported strategy; ${ }^{23}$ four models were tested (a single-factor model and three-two-factor models that compared different item-factor loading: Table S1), and the best fit was found for a two-factor model consisting of four nonsomatic (anhedonia, depressed mood, feeling of worthlessness, thoughts of death) and five somatic (fatigue, appetite changes, sleep difficulties, concentration difficulties, psychomotor agitation and retardation) items. This model showed a close fit $\left(\chi^{2}=196.9\right.$, degrees of freedom $=26$, $P<.001 ; \quad$ RMSEA $=0.047,90 \%$ confidence interval $=$ 0.04-0.05, Comparative Fit Index $=0.991$, Tucker-Lewis Index $=0.987)($ Table S2). Testing the model in individuals with and without T2DM separately showed good fit in both groups (data not shown). Formal testing for measurement invariance across both groups showed support for strong (scalar) factorial invariance.

\section{Diagnostic Algorithm of the PHQ-9}

A diagnostic algorithm can be used as an alternative sumscore for the PHQ-9; the core symptoms of depressive disorder (depressed mood, anhedonia) have to be present along with five or more other items for more than half of the days. ${ }^{29}$ This algorithm had worse consistency with MINI depressive disorder than the continuous total score (data not shown).

\section{Sensitivity Analyses}

Because the use of psychoactive drugs (Table 1) could affect the scoring of the PHQ-9, a sensitivity analyses was performed excluding participants who used anxiolytics, antidepressants, or antipsychotics. This did not materially change the results (data not shown). 
Table 1. Baseline Characteristics $(\mathrm{N}=2,997)$

\begin{tabular}{|c|c|c|c|c|c|c|}
\hline \multirow[b]{2}{*}{ Characteristic } & \multicolumn{3}{|c|}{ Without T2DM } & \multicolumn{3}{|c|}{ With T2DM } \\
\hline & $\begin{array}{c}\text { Total, } \\
\mathrm{n}=2,204\end{array}$ & $\begin{array}{c}\text { No Depression, } \\
n=2,116\end{array}$ & $\begin{array}{l}\text { Depression, } \\
\quad \mathrm{n}=\mathbf{8 8}\end{array}$ & $\begin{array}{l}\text { Total, } \\
\mathrm{n}=793\end{array}$ & $\begin{array}{l}\text { No Depression, } \\
n=732\end{array}$ & $\begin{array}{c}\text { Depression, } \\
n=61\end{array}$ \\
\hline \multicolumn{7}{|l|}{ Demographic } \\
\hline Male, n (\%) & $984(44.6)^{\mathrm{C}}$ & $949(44.8)^{\mathrm{e}}$ & $35(39.8)^{j}$ & $534(67.3)$ & $496(67.8)$ & $38(62.3)$ \\
\hline Age, mean $\pm S D$ & $58.6 \pm 8.1^{c}$ & $58.7 \pm 8.2^{\mathrm{e}}$ & $57.2 \pm 7.7^{i}$ & $62.4 \pm 7.7$ & $62.5 \pm 7.6$ & $60.6 \pm 8.1$ \\
\hline Medium to high & $72.6^{\mathrm{c}}$ & 73.4 & 55.9 & 54.7 & 55.5 & 45.9 \\
\hline Partner, n (\%) & $1,857(85.3)^{\mathrm{a}}$ & $1,787(85.4)$ & $70(81.4)$ & $637(80.3)$ & $594(83.1)^{i}$ & $43(70.5)$ \\
\hline Lifetime depression, n (\%) & $682(30.9)$ & $632(29.9)^{\mathrm{h}}$ & $50(56.8)$ & $262(33.0)$ & $228(31.1)^{\mathrm{k}}$ & $34(55.7)$ \\
\hline $\begin{array}{l}\text { Patient Health Questionnaire-9 score, } \\
\text { mean } \pm \text { SD }\end{array}$ & $2.6 \pm 3.0^{C}$ & $2.3 \pm 2.5^{\mathrm{d}, \mathrm{h}}$ & $9.2 \pm 5.7$ & $3.3 \pm 4.2$ & $2.6 \pm 3.1^{k}$ & $10.7 \pm 7.3$ \\
\hline \multicolumn{7}{|l|}{ Lifestyle factors } \\
\hline Former & 49.5 & 50.0 & 50.0 & 56.5 & 56.7 & 55.0 \\
\hline Current & 12.0 & 11.8 & 19.8 & 15.3 & 14.3 & 26.7 \\
\hline Alcohol (drinks/wk), n (\%) & S & $\mathrm{e}, \mathrm{g}$ & & & & \\
\hline None & 14.0 & 13.5 & 26.5 & 28.6 & 27.7 & 39.3 \\
\hline Moderate (women $\leq 7$, men $\leq 14$ ) & 57.2 & 57.6 & 48.2 & 51.8 & 52.7 & 41.0 \\
\hline High (women $>7$, men $>14$ & 28.8 & 28.9 & 25.3 & 19.6 & 19.6 & 19.7 \\
\hline \multicolumn{7}{|l|}{ DM-related characteristics } \\
\hline History of cardiovascular disorders, n (\%) & $259(12.0)^{\mathrm{C}}$ & $250(12.1)^{\mathrm{e}}$ & $9(10.6)^{j}$ & $212(27.8)$ & $194(27.6)$ & $18(31.0)$ \\
\hline Hypertension, n (\%) & $998(45.4)^{c}$ & $953(45.1)^{\mathrm{e}}$ & $45(51.1)^{k}$ & $660(83.2)$ & $610(83.3)$ & $50(82.0)$ \\
\hline Duration of T2DM & & & & $8.3 \pm 7.0$ & $8.2 \pm 6.9$ & $9.8 \pm 7.6$ \\
\hline $\begin{array}{l}\text { Glycosylated hemoglobin, } \mathrm{mmol} / \mathrm{mol} \text {, } \\
\text { mean } \pm \text { SD }\end{array}$ & $36.6 \pm 4.0^{\mathrm{C}}$ & $36.6 \pm 4.1^{\mathrm{e}}$ & $36.7 \pm 3.7^{k}$ & $51.7 \pm 11.1$ & $51.5 \pm 10.7^{i}$ & $54.8 \pm 14.6$ \\
\hline \multicolumn{7}{|l|}{ Medication, n (\%) } \\
\hline
\end{tabular}

Depression was diagnosed using the Mini-International Neuropsychiatric Interview.

$\mathrm{SD}=$ standard deviation.

${ }^{\mathrm{a}} \mathrm{P}<.05$ versus type 2 diabetes mellitus (T2DM).

${ }^{\mathrm{b}} P<.01$ versus T2DM.

${ }^{\mathrm{c}} P<.001$ versus T2DM.

${ }^{\mathrm{d} P}<.05$ versus $\mathrm{T} 2 \mathrm{DM}$ and no depression.

${ }^{\mathrm{e}} P<.001$ versus T2DM and no depression.

${ }^{\mathrm{f}} P<.05$ versus no T2DM and depression.

${ }^{\mathrm{g}} \mathrm{P}<.01$ versus no T2DM and depression.

${ }^{\mathrm{h}} \mathrm{P}<.001$ versus no T2DM and depression.

${ }^{\mathrm{i}} P<.05$ versus T2DM and depression.

${ }^{\mathrm{i}} P<.01$ versus $\mathrm{T} 2 \mathrm{DM}$ and depression.

${ }^{\mathrm{k}} P<.001$ versus T2DM and depression.

\section{DISCUSSION}

The PHQ-9 performed similarly in individuals with and without T2DM in the current study. In individuals with and without T2DM, a PHQ-9 cutoff of 5 was found to distinguish far better between individuals with and without depression as diagnosed using the MINI structured interview than the traditional cutoff 10 . Further psychometric evaluation demonstrated a similar factor structure of the PHQ-9 for individuals with and without T2DM, suggesting two correlated factors (affective and somatic symptoms).

The application of a cutoff score of 5 for the PHQ-9 demonstrated sensitivity of $92.3 \%$ and specificity of $70.4 \%$ in individuals with T2DM and comparable results in individuals without T2DM. The sensitivity of the traditional PHQ-9 cutoff score of $10^{17}$ was below acceptable values, in contrast to the majority of earlier studies. To the knowledge of the authors of the current study, this is the first study to investigate a different ratio of sensitivity and 
Table 2. Cross Table of Diagnosis of Depressive Disorder as Assessed Using the Mini-International Neuropsychiatric Interview (MINI) Versus Depressive Symptoms as Assessed Using the Patient Health Questionnaire (PHQ)-9 According to Type 2 Diabetes Mellitus Status

\begin{tabular}{ccc} 
& \multicolumn{2}{c}{ MINI } \\
\cline { 2 - 3 } T2DM & No Depressive Disorder & Depressive Disorder \\
\hline No & & \\
PHQ-9 $<10$ & $2,077(98.2 \%)$ & $51(58.0 \%)$ \\
PHQ-9 $\geq 10$ & $39(1.8 \%)$ & $37(42.0 \%)$ \\
Yes & $701(95.8 \%)$ & $35(57.4 \%)$ \\
PHQ-9 $<10$ & $31(4.2 \%)$ & $26(42.6 \%)$ \\
\hline PHQ-9 $\geq 10$ & & \\
\hline
\end{tabular}

Table 3. Diagnostic Performance of Patient Health Questionnaire (PHQ)-9 for the Detection of Minor and Major Depressive Disorder

\begin{tabular}{|c|c|c|c|c|c|c|c|c|}
\hline \multirow[b]{3}{*}{ Performance } & \multicolumn{8}{|c|}{ PHQ-9 Score } \\
\hline & \multicolumn{4}{|c|}{ No T2DM (\%) } & \multicolumn{4}{|c|}{ T2DM (\%) } \\
\hline & $\geq 3$ & $\geq 5$ & $\geq 7$ & $\geq 10$ & $\geq 3$ & $\geq 5$ & $\geq 7$ & $\geq 10$ \\
\hline Prevalence $^{\mathrm{a}}$ & 38.8 & 27.8 & 9.0 & 3.4 & 41.9 & 33.0 & 15.9 & 7.3 \\
\hline Sensitivity & 96.4 & 92.9 & 78.6 & 42.0 & 97.6 & 92.3 & 81.0 & 42.6 \\
\hline Specificity & 62.7 & 73.9 & 92.8 & 98.2 & 61.3 & 70.4 & 87.7 & 95.7 \\
\hline $\begin{array}{l}\text { Positive } \\
\text { predictive value }\end{array}$ & 6.3 & 8.5 & 22.2 & 48.7 & 12.3 & 14.9 & 27.0 & 45.6 \\
\hline $\begin{array}{l}\text { Negative } \\
\text { predictive value }\end{array}$ & 99.6 & 99.7 & 99.4 & 97.6 & 99.8 & 99.4 & 98.8 & 95.8 \\
\hline
\end{tabular}

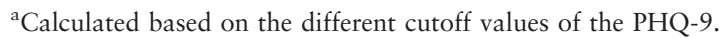

specificity based on screening characteristics, which also explains the difference from previous studies.

These results show that the PHQ-9 can best be conceived as a first-stage screening tool in daily DM care to identify individuals in need of further psychological evaluation. To maximize the probability of detection of depression in individuals with T2DM, high sensitivity seems preferable over high specificity, even though this means accepting the inclusion of some false-positive cases (moderate specificity), assuming that a second, more in-depth assessment will filter out the latter. ${ }^{25}$ In current DM care, treatment is focused on glycemic control, dietary advice, and cardiovascular risk management. ${ }^{30}$ Psychopathological problems in individuals with T2DM are frequently overlooked. Implementation of the PHQ-9 as a screening instrument could help to overcome this, because self-administered questionnaires have proven their value in screening for depression in other populations. ${ }^{21,23,24}$ The questionnaire can be completed before a doctor's visit, and those who screen positive (according to the current findings, a score of $\geq 5$ ) can be referred for further psychiatric evaluation. This approach is likely to be most efficient and economic and improve detection and treatment of depression in T2DM and may also improve DM care by preventing depression-mediated effects on diabetic complications. ${ }^{6-10}$

To the knowledge of the authors, this is the first study to conduct confirmatory factor analyses in individuals with and without T2DM. ${ }^{23,24}$ The factor structure of somatic and nonsomatic items of the PHQ-9 showed no difference in individuals with and without T2DM, despite the presence of a chronic somatic disease in those with T2DM, which could have led to higher scores for the somatic items. Thus, the full questionnaire is useful regardless of T2DM status.

This study is based on the Maastricht Study, a large, observational, population-based cohort study, which has several strengths. Most notably, its sample size allows the psychometric properties of the PHQ-9 to be studied properly given the low prevalence of major depression in the population. In addition, state-of-the-art and validated measures were used to assess DM and depression status.

Certain limitations of the study should be acknowledged. The study population was mainly Caucasian, which limits extrapolation to non-Caucasian populations. Furthermore, the recruitment strategy could have led to selection bias in the sense that individuals with more-severe depressive disorder or DM or with greater comorbidity were less likely to participate in the Maastricht Study. The prevalence of depression might therefore be an underestimation and may be higher in an unselected population with T2DM, although it is comparable with previously published data. ${ }^{2-5}$ The lower PHQ-9 cutoff used in the final analyses would detect these more severely depressed individuals.

\section{CONCLUSION}

The PHQ-9 performs well as a depression screening tool in individuals with and without T2DM individuals based on the cutoff value of 5 and can consequently be used in a two-stage screening approach in primary DM care. Possible early detection of depression in individuals with T2DM may improve outcomes in terms of mental and physical health.

\section{ACKNOWLEDGMENTS}

This study is supported by the European Regional Development Fund as part of OP-ZUID; the Province of Limburg; the department of Economic Affairs of the Netherlands (grant 31O.041); Stichting the Weijerhorst, the Pearl String Initiative Diabetes; the Cardiovascular Center Maastricht Cardiovasculair Research Institute Maastricht; School of Nutrition, Toxicology and Metabolism; Stichting Annadal; Health Foundation Limburg; and unrestricted grants from Janssen, Novo Nordisk, and Sanofi.

Conflict of Interest: None.

Author Contributions: Janssen: study concept and design, analysis, interpretation, writing of manuscript. Köhler, Schram: data acquisition, conceptualization, study concept and design, analysis, interpretation, writing of manuscript. Stehouwer, Schaper, Dagnelie, Sep, Henry, van der Kallen, Verhey: data acquisition, conceptualization, data interpretation. All authors: creation and revision of manuscript. 
Sponsor's Role: There was no sponsor involvement in data collection, analysis, interpretation, or manuscript preparation.

\section{REFERENCES}

1. Palinkas LA, Wingard DL, Barrett-Connor E. Chronic illness and depressive symptoms in the elderly: A population-based study. J Clin Epidemiol 1990;43:1131-1141.

2. Ali S, Stone MA, Peters JL et al. The prevalence of co-morbid depression in adults with type 2 diabetes: A systematic review and meta-analysis. Diabet Med 2006;23:1165-1173.

3. Sapozhnikova IE, Tarlovskaia EI, Sobolev AA et al. [Frequency and specific features of depressive disorders in patients with type 2 diabetes mellitus]. Klin Med 2010;88:43-46

4. Lloyd CE, Pambianco G, Orchard TJ. Does diabetes-related distress explain the presence of depressive symptoms and/or poor self-care in individuals with type 1 diabetes? Diabet Med 2010;27:234-237.

5. Anderson RJ, Freedland KE, Clouse RE et al. The prevalence of comorbid depression in adults with diabetes: A meta-analysis. Diabetes Care 2001;24:1069-1078.

6. Schram MT, Baan CA, Pouwer F. Depression and quality of life in patients with diabetes: A systematic review from the European Depression in Diabetes (EDID) research consortium. Curr Diabetes Rev 2009;5:112-119.

7. Pouwer F, Nefs G, Nouwen A. Adverse effects of depression on glycemic control and health outcomes in people with diabetes: A review. Endocrinol Metab Clin North Am 2013;42:529-544.

8. Ciechanowski PS, Katon WJ, Russo JE. Depression and diabetes: Impact of depressive symptoms on adherence, function, and costs. Arch Intern Med 2000; $160: 3278-3285$

9. Lustman PJ, Anderson RJ, Freedland KE et al. Depression and poor glycemic control: A meta-analytic review of the literature. Diabetes Care 2000;23:934-942.

10. Rubin RR, Ciechanowski P, Egede LE et al. Recognizing and treating depression in patients with diabetes. Curr Diab Rep 2004;4:119-125.

11. Moulton CD, Pickup JC, Ismail K. The link between depression and diabetes: The search for shared mechanisms. Lancet Diabetes Endocrinol 2015;3:461-471.

12. Park M, Katon WJ, Wolf FM. Depression and risk of mortality in individuals with diabetes: A meta-analysis and systematic review. Gen Hosp Psychiatry 2013;35:217-225.

13. Baumeister H, Hutter N, Bengel J. Psychological and pharmacological interventions for depression in patients with diabetes mellitus and depression. Cochrane Database Syst Rev 2012;12:CD008381.

14. de Groot M, Anderson R, Freedland KE et al. Association of depression and diabetes complications: A meta-analysis. Psychosom Med 2001;63:619-630.

15. American Diabetes Association. Standards of medical care in diabetes2014. Diabetes Care 2014;37(Suppl 1):S14-S80.

16. Wittkampf KA, Naeije L, Schene AH et al. Diagnostic accuracy of the mood module of the Patient Health Questionnaire: A systematic review. Gen Hosp Psychiatry 2007;29:388-395.

17. Kroenke K, Spitzer RL, Williams JB. The PHQ-9: Validity of a brief depression severity measure. J Gen Intern Med 2001;16:606-613.

18. Khamseh ME, Baradaran HR, Javanbakht A et al. Comparison of the CES$\mathrm{D}$ and PHQ-9 depression scales in people with type 2 diabetes in Tehran, Iran. BMC Psychiatry 2011;11:61.
19. Lamers F, Jonkers CC, Bosma H et al. Summed score of the Patient Health Questionnaire-9 was a reliable and valid method for depression screening in chronically ill elderly patients. J Clin Epidemiol 2008;61:679-687.

20. van Steenbergen-Weijenburg KM, de Vroege L, Ploeger RR et al. Validation of the PHQ-9 as a screening instrument for depression in diabetes patients in specialized outpatient clinics. BMC Health Serv Res 2010;10:235.

21. van der Zwaan GL, van Dijk SE, Adriaanse MC et al. Diagnostic accuracy of the Patient Health Questionnaire-9 for assessment of depression in type II diabetes mellitus and/or coronary heart disease in primary care. J Affect Disord 2016;190:68-74.

22. Sheehan DV, Lecrubier Y, Sheehan KH et al. The Mini-International Neuropsychiatric Interview (M.I.N.I.): The development and validation of a structured diagnostic psychiatric interview for DSM-IV and ICD-10. J Clin Psychiatry 1998;59(Suppl 20):22-33; quiz 4-57.

23. Elhai JD, Contractor AA, Tamburrino $M$ et al. The factor structure of major depression symptoms: A test of four competing models using the Patient Health Questionnaire-9. Psychiatry Res 2012;199:169-173.

24. Krause JS, Reed KS, McArdle JJ. Factor structure and predictive validity of somatic and nonsomatic symptoms from the Patient Health Questionnaire9: A longitudinal study after spinal cord injury. Arch Phys Med Rehabil 2010;91:1218-1224.

25. Grimes DA, Schulz KF. Uses and abuses of screening tests. Lancet 2002;359:881-884.

26. Schram MT, Sep SJ, van der Kallen CJ et al. The Maastricht Study: An extensive phenotyping study on determinants of type 2 diabetes, its complications and its comorbidities. Eur J Epidemiol 2014;29:439-451.

27. Definition and Diagnosis of Diabetes Mellitus and Intermediate Hyperglycaemia. Geneva, Switzerland: World Health, Organization, 2006.

28. van de Schoot R, Hoijtink H, Hallquist MN et al. Bayesian evaluation of inequality-constrained hypotheses in SEM models using Mplus. Struct Equ Modeling 2012;19:593-609.

29. PHQ-screeners [on-line]. Available at https://phqscreeners.pfizer.edrupalgardens.com/sites/g/files/g10016261/f/201412/instructions.pdf Accessed June 22, 2016.

30. Fauci A, Braunwald E, Kasper D et al. Harrison's Principles of Internal Medicine, 17th Ed. London: McGraw-Hill, 2008.

\section{SUPPORTING INFORMATION}

Additional Supporting Information may be found in the online version of this article:

Table S1. Factor Models.

Table S2. Comparison-of-Fit Statistics for the Four Patient Health Questionnaire-9 Factor Analytical Models in the Total Group.

Figure S1. Flowchart.

Figure S2. Receiver operating characteristic curve in total group.

Please note: Wiley-Blackwell is not responsible for the content, accuracy, errors, or functionality of any supporting materials supplied by the authors. Any queries (other than missing material) should be directed to the corresponding author for the article. 